

\title{
Prevalence and Antifungal Susceptibility Pattern of Candida species Isolated from Patients with Urinary Tract Infections Osinupebi OA ${ }^{1}$, Adeosun OV², Lawal IA*3
}

1Department of Medical Microbiology and Parasitology, Olabisi Onabanjo University, Ago Iwoye, Nigeria 2Department of Medical Microbiology and Parasitology, Lagos State University Teaching Hospital, Ikeja, Lagos, Nigeria

${ }^{3}$ Department of Medical Microbiology and Parasitology, Olabisi Onabanjo University, Teaching Hospital, Sagamu, Nigeria

*Correspondence: Dr IA Lawal, Department of Medical Microbiology and Parasitology, Olabisi Onabanjo University, Teaching Hospital, Sagamu, Nigeria. E-mail: drlawalismail@gmail.com; ORCID - https://orcid.org/0000-0001-8116-280X.

\begin{abstract}
Background: The presence of Candida species in the urine is termed candiduria, and it is a common form of urinary tract infection (UTI). Many other species of Candida organism apart from Candida albicans are known with increasing the occurrence of resistance to available antifungal agents.

Objectives: To determine the prevalence and sensitivity pattern of Candida isolates obtained from urine samples of diagnosed urinary tract infections.

Methods: Midstream urine of patients attending the Lagos University Teaching Hospital, Ikeja Lagos, were collected and inoculated on Sabouraud Dextrose Agar (SDA). Microbiological processing was done with Gram reaction, germ tube test, CHROME agar TM and sugar fermentation test using API 32C system. Antifungal susceptibility tests were done using the agar disc diffusion method.

Results: Candida species were obtained from 36 (12.9\%) of 280 patients with UTI. Candida albicans (CA) had the highest frequency $(12 ; 33.3 \%)$ compared to 24 (66.7\%) for Non-albicans Candida (NAC). The speciation of Candida using Chrome Agar showed some misidentification from the API32C identification, but there was a significant correlation between API32C and Chrome Agar methods $(r=0.9793)$. Half of the $C$. albicans species were sensitive to fluconazole while $C$. hellenica was only sensitive to Nystatin. The C. parapsilopsis had the highest susceptibility pattern, with $86 \%$ and $71 \%$ for fluconazole and ketoconazole, respectively. Generally, ketoconazole had the highest effectiveness on Candida species.

Conclusion: This study demonstrated the role of Candida species in UTIs and their high susceptibility to ketoconazole.
\end{abstract}

Key words: Candida albicans, Candiduria, Non-albicans Candida, Urinary Tract Infections.

\section{Introduction}

Candiduria is known as the most frequent nosocomial fungal infection worldwide. Candida albicans is the most common cause of nosocomial fungal urinary tract infections. [1]
Over one hundred and fifty million people worldwide experience an episode of candiduria yearly. ${ }^{[2]}$ The presence of yeast or Candida species in the urine is termed candiduria. It can be detected by methods such as microscopy showing pseudohyphae and budding of yeast cells and cultural and 
genetic techniques. The risk factors include urinary tract instrumentation, surgical procedures, antibiotic use, advanced age, female gender, intensive care unit (ICU) admission, immunosuppressive therapy, and prolonged hospitalisation. ${ }^{[3]}$

The leading three species of Candida include $C$. albicans, C. glabrata and C. tropicalis, respectively. Genitourinary tract infections consist of different infections, including asymptomatic and symptomatic candiduria, cystitis, pyelonephritis, candida balanitis and vulvovaginal candidiasis. [1] The aetiology of candiduria changes with greater than $50 \%$ of urinary isolates caused by the Non-albicans Candida (NAC), and candiduria can be a marker for a serious underlying illness. ${ }^{[4]}$

However, rapid change in the role of Candida species in the causation of urinary tract infections in some countries has been noted. In Ghana, C. glabrata is dominant among the isolated Candida species relative to C. albicans [46 (27.7\%) against 59 (35.5\%)]. [5] In Nasarawa State, Nigeria, C. tropicalis was the most frequently isolated agent of candiduria, followed by $C$. albicans and C. utilis, respectively. [6]

Antifungal agents play a significant role in the treatment $\mathrm{f}$ of UTI. An increasing number of antifungal agents can be used to treat mycotic infections. ${ }^{[2,7]}$ The treatment of fungal diseases is compromised by the emergence of antifungal drug resistance, which was hitherto considered a rare occurrence. Currently, antifungal drug resistance is now on the rise. The evolution of multidrug-resistant organisms refractory to several different classes of antifungal agents is most concerning, especially among common Candida species. The resistance mechanisms include inherently reduced susceptibility and those acquiring resistance during therapy. ${ }^{[8]}$

The classes of the currently available drugs belong to the groups of polyenes, azoles and echinocandins. Polyenes and azoles act on the cell membrane and echinocandins disrupt the fungal cell wall. Other classes are ally amines and antimetabolites. ${ }^{[9]}$ Recently, an increase in the number of Candida species resistant to antifungal drugs has been recognised worldwide; C. tropicalis and C. pararapsilosis are both generally susceptible to azoles, whereas C. glabrata and C. krusei are intrinsically more resistant to antifungal agents, particularly to Fluconazole. [8] Therefore, this study was conducted to determine the prevalence, and antifungal sensitivity pattern of Candida isolates obtained from urine samples of diagnosed urinary tract infections.

\section{Methods}

The study adopted a cross-sectional design, and the study involved consenting patients aged more than 16 years with the provisional diagnosis of UTI from July to December 2014.

The sample size was determined using Fisher's formula:

$$
\mathrm{N}=\frac{\mathrm{t}^{2} \times \mathrm{p}(1-\mathrm{p})}{\mathrm{M}^{2}}
$$

Where:

$\mathrm{N}=$ required minimum sample size.

$\mathrm{t}=$ confidence level at $95 \%$ (standard value of 1.96).

$\mathrm{p}=$ estimated prevalence of candiduria in patients with UTI in the project area.

$M=$ margin of error at $5 \%$ (standard value of $0.05)$.

For this study:

$\mathrm{N}=(1.96)^{2} \times 0.2 \times(1-0.2) /(0.05)^{2}$

$\mathrm{N}=245.86$

An additional $10 \%$ of this was added to adjust for attrition. Therefore, the final minimum sample size was 280 .

Ethical approval for the study was obtained from the Lagos State University Teaching Hospital Health Research Ethical Committee, HREC, with reference number 
LREC/10/06/303. Informed consent was also obtained from all the patients.

Mid-stream urine samples were collected from the 280 adult patients with the provisional diagnosis of UTI (symptomatic) attending Outpatient clinics at the Lagos State University Teaching Hospital, Ikeja. Excluded from the study were patients aged less than 16 years and those with no features of UTI. The urine samples were examined macroscopically for colour and turbidity, centrifugation was done at $1500 \mathrm{rpm}$ for five minutes, and wet preparation of the sediment was examined microscopically under X4 and X10 lenses. The urine samples were Gram-stained and cultured on Sabouraud Dextrose Agar (SDA), incubated at $37^{\circ} \mathrm{C}$ for $24-48$ hours. Colonies were read based on their colonial appearances, large size, shape, colour, elevation and consistency. The isolates were identified using Gram reaction, Germ tube test, and Chrome agar, while Candida biochemical identification was carried out using the API32C system. The Germ tube test was done by dispensing $0.5 \mathrm{mls}$ of human serum in Khan tubes and was incubated with five colonies of Candida isolates for three hours. One drop from the suspension was placed on a grease-free glass slide, and a drop of lactophenol cotton blue was added and examined for the formation of a germ tube. Sugar fermentation tests were also performed using the API 32C system. Purified isolate suspension was made to match turbidity equivalent to $2 \mathrm{McF}$ arland standard, and $250 \mu \mathrm{l}$ was transferred into an ampoule of the API C medium. A volume of $135 \mu$ l of the yeast basal medium suspension was pipetted into each freeze-dried sugar wells and incubated at $30^{\circ} \mathrm{C}$ for 24 hours. Visual turbidity indicated growth, while lack of turbidity indicated no growth. The result was correlated with the API 32C identification software. The isolates were aseptically inoculated on Chrome agar and were incubated at $37^{\circ} \mathrm{C}$ for 48 hours. According to the manufacturer's instructions, the colonies were then identified based on colours.

Antifungal susceptibility tests were done using the agar disc diffusion method. The inoculum suspension was prepared and matched with $0.5 \mathrm{McF}$ arland standard. The standardised suspension was flooded on the surface of the plate, the excess was drained, and antibiotic discs were placed and incubated at $37{ }^{\circ} \mathrm{C}$ for $24-48$ hours. Antifungal discs used included Itraconazole $(8 \mu \mathrm{g})$, Ketoconazole $(10 \mu \mathrm{g})$, Fluconazole $(25 \mu \mathrm{g})$, Terbinafine $(30 \mu \mathrm{g})$, Griseofulvin $(25 \mu \mathrm{g})$ and Nystatin $(100 \mu \mathrm{g})$. The zones of inhibition were measured and interpreted using the National Committee for Clinical Laboratory Standards (NCCLS) guidelines. ${ }^{[10]}$ The Control strain used was Candida albicans ATCC 10231.

The data were analysed using the Statistical Package for Social Sciences (SPSS) Windows version 21.0. The socio-demographic characteristics of the participants were presented using frequency tables. Continuous variables were summarised using descriptive statistics such as the mean and standard deviation at $95 \%$ Confidence Interval (CI). The level of statistical significance was set at $\mathrm{p}<0.05$.

\section{Results}

Out of 280 urine samples, there were 121 (43.2\%) males and 159 (56.8\%) females (Table I). A total of 36 species of Candida were isolated, representing $12.9 \%$ of all the patients with UTI. These 36 isolates were obtained from the urine samples of $10(27.8 \%)$ males and $26(72.2 \%)$ females. Most of the isolates were obtained from people in the age group of $31-40$ years $(8 ; 22.22 \%)$, while the lowest yield was obtained at age $>80$ years $(1 ; 2.78)$ (Table II). 
Table I: Age and sex distribution of patients with Urinary Tract Infections

\begin{tabular}{|c|c|c|c|}
\hline \multirow{2}{*}{$\begin{array}{l}\text { Age } \\
\text { (Years) }\end{array}$} & \multicolumn{2}{|c|}{ Sex } & \multirow[t]{2}{*}{ Total } \\
\hline & Male & Female & \\
\hline $16-20$ & $14(44.0)$ & $14(56.0)$ & $28(8.9)$ \\
\hline $21-30$ & $23(46.0)$ & $27(54.0)$ & 50 (17.9) \\
\hline $31-40$ & 19 (29.7) & 45 (70.3) & 64 (22.9) \\
\hline $41-50$ & $11(30.6)$ & $25(69.4)$ & 36 (12.9) \\
\hline $51-60$ & $14(38.9)$ & $22(61.1)$ & 36 (12.9) \\
\hline $61-70$ & $26(66.7)$ & 13 (33.3) & 39 (13.9) \\
\hline $71-80$ & $10(45.5)$ & $12(54.5)$ & $22(7.8)$ \\
\hline$>80$ & 7 (87.5) & 1 (12.5) & $8(2.7)$ \\
\hline Total & $121(43.2)$ & 159 (56.8) & $280(100.0)$ \\
\hline
\end{tabular}

Table II: Age and sex distribution of patients with Candiduria

\begin{tabular}{llll}
\hline $\begin{array}{l}\text { Age Group } \\
\text { (Years) }\end{array}$ & \multicolumn{2}{c}{ Sex } & Total \\
\hline & Male & Female & \\
$16-20$ & $1(33.3)$ & $2(66.7)$ & $3(8.3)$ \\
$21-30$ & $1(20.0)$ & $5(80.0)$ & $6(13.9)$ \\
$31-40$ & $3(37.5)$ & $5(62.5)$ & $8(22.2)$ \\
$41-50$ & $2(33.3)$ & $4(66.7)$ & $6(16.7)$ \\
$51-60$ & $1(20.0)$ & $4(80.0)$ & $5(13.9)$ \\
$61-70$ & $1(20.0)$ & $4(80.0)$ & $5(13.9)$ \\
$71-80$ & $1(33.3)$ & $2(66.7)$ & $3(8.3)$ \\
$>80$ & $0(0.0)$ & $1(100.0)$ & $1(2.8)$ \\
Total & $\mathbf{1 0 ( 2 7 . 8 )}$ & $\mathbf{2 6 ( 7 2 . 2 )}$ & $\mathbf{3 6 ( 1 0 0 . 0 )}$ \\
\hline
\end{tabular}

Candida albicans (CA) had the highest prevalence (33.3\%). Non-albicans Candida (NAC) included C. tropicalis $(25.0 \%)$, C. parapsilosis $(19.4 \%)$, C. grabrata $(5.6 \%), C$. hellenica $(2.8 \%)$ and S. cerevisiae $(2.8 \%)$ as shown in Table III. The speciation of Candida species using Chrome Agar showed some misidentification from AP $\mathrm{I} 32 \mathrm{C}$ results in 6 $(16.7 \%)$ cases. NACs (C. tropicalis, C. parapsilosis, C. krusei, C. kefyr and C. glabrata) were misidentified. All CA were identified correctly (Table IV). Figure 1 shows the correlation between API 32C and Chrome Agar methods of speciation, and there was a significant correlation between API 32C and Chrome Agar methods $(r=0.9793)$.
Table V shows that all the Candida species isolated were resistant to griseofulvin; only $50 \%$ of C. albicans were sensitive to fluconazole, and C. hellenica was only sensitive to Nystatin. Candida glabrata had the highest susceptibility pattern to itraconazole and ketoconazole with $50 \%$ and $100 \%$ susceptibility rates, respectively. C. parapsilosis had the highest susceptibility rates $(86 \%$ and $71 \%$ ) to fluconazole and ketoconazole, respectively. C. albicans had $50 \%$ susceptibility to fluconazole but $25 \%$ susceptibility to itraconazole. Ketoconazole had the highest effectiveness on Candida species with activities against six Candida species. 
Table III: Distribution of Candida species isolated from patients with urinary tract infections.

\begin{tabular}{lll}
\hline Candida species & Frequency & Percentage \\
\hline C. albicans & 12 & 33.3 \\
C. tropical & 9 & 25.0 \\
C. parapsilosis & 7 & 19.4 \\
C. grabrata & 2 & 5.6 \\
C. crusei & 2 & 5.6 \\
C. kefry & 2 & 5.6 \\
C. hellenica & 1 & 2.8 \\
Saccharomyces cerevisiae & 1 & 2.8 \\
Total & 36 & $\mathbf{1 0 0}$ \\
\hline
\end{tabular}

Table IV: Identification of Candida species using the Chrome Agar and API 32C methods

\begin{tabular}{lll}
\hline Candida species & \multicolumn{2}{c}{ Chrome Agar } \\
\hline & Candida & API 32C \\
C. albicans & 12 & 12 \\
C. tropical & 10 & 9 \\
C. parapsilosis & 9 & 7 \\
C. grabrata & 3 & 2 \\
C. crusei & 1 & 2 \\
C. kefry & 1 & 2 \\
C. hellenica & 0 & 1 \\
Saccharomyces cerevisiae & 0 & 1 \\
Total & 36 & 36 \\
\hline
\end{tabular}

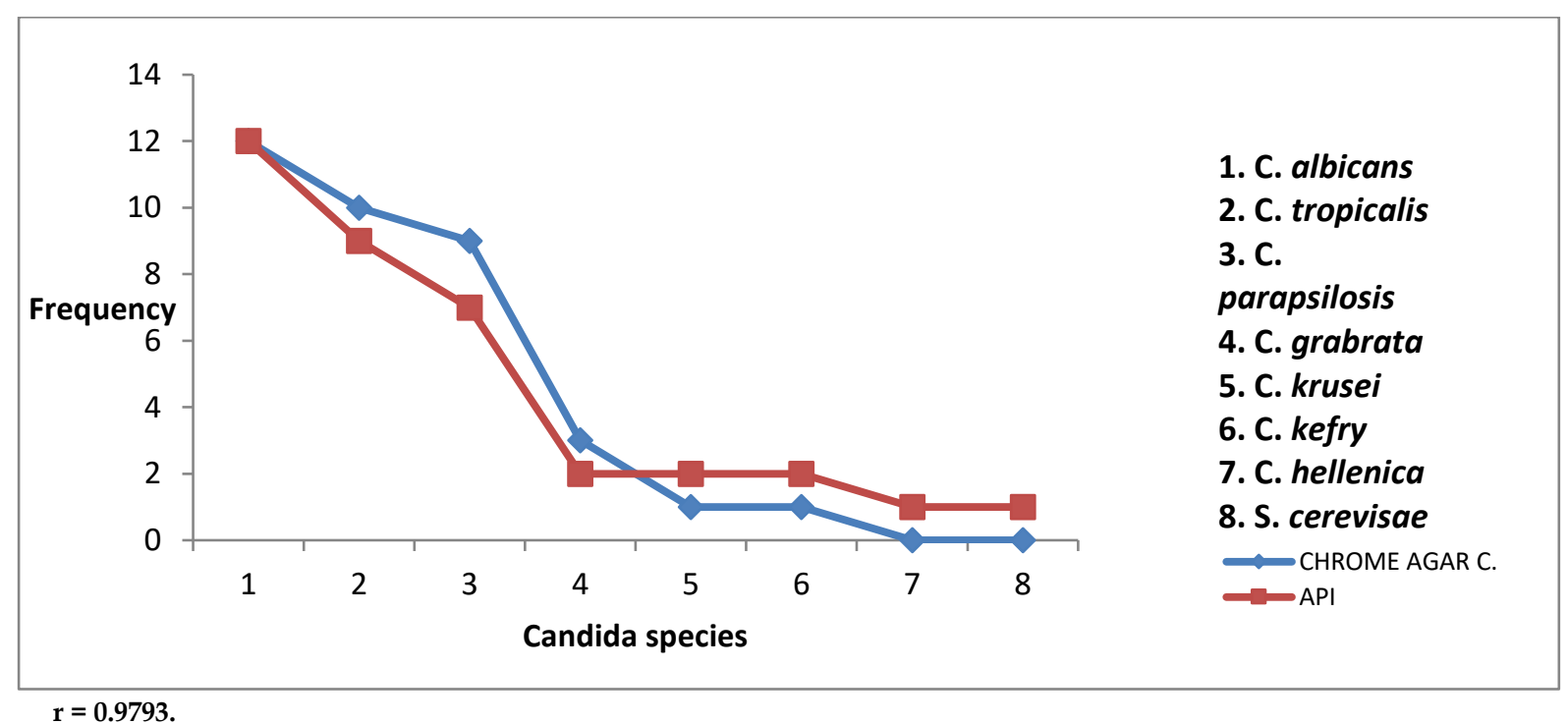

Figure 1: Correlation between API 32C and Chrome Agar methods

\section{Discussion}

Urinary tract infection is one of the microbial infections affecting all age groups worldwide, and candiduria is a common fungal form of
UTI. In the present study, most of the patients presenting with clinical features of UTI were females. This finding agrees with the previous work of Josiah et al. in Calabar, Nigeria, who reported a higher incidence of UTI among 
females than males. [11] The sex-related predominance could be due to the shorter length of the female urethra and its closeness to the anus.

The present study showed candiduria in $12.9 \%$ of patients with UTI in agreement with the report of Gharaghani et al. in 2018, which showed that candiduria in $10-15 \%$ of UTI cases. [12] The prevalence of candiduria was higher among females compared with males. This pattern is similar to the finding of Yismaw et al., that significant candiduria was strongly associated with the female sex. ${ }^{[13]}$ The sex distribution of the 36 Candida species isolated in the present study showed female preponderance similar to the findings in a survey carried out in Keffi, northern Nigeria where the prevalence among female students was four times higher than among the males. [6]

C. albicans recorded the highest incidence rate of $33.3 \%$ among the species of Candida isolated. This rate is relatively lower compared with the report of Akortha et al., which recorded a prevalence of $63.9 \%$ for C. albicans in Benin City. [14] The result of the present study is in contrast with the findings of Okungbowa et al., who reported C. glabrata as the most common Candida species among symptomatic individuals in Nigerian cities. [15] Also, in this study, $67.7 \%$ of the cases were non-albicans Candida species, different from the reports from Hollandia et al., with an overall prevalence of non-albicans Candida of $21 \%$ and of which $89 \%$ were C. glabrata. [16] These variations in the report may be attributed to the method used in the identification and differences in population types. ${ }^{[17]}$ However, the findings in the present study are similar to a Turkish with prevalence rates of $44 \%, 18 \%$ and $20 \%$ for C. albicans, C. glabrata and C. tropicalis. [18] Furthermore, a study in Iran reported a prevalence of $77.4 \%$ for Candida albicans. [19]

Table V: Susceptibility pattern of Candida species to selected antifungal agents

\begin{tabular}{|c|c|c|c|c|c|c|c|c|c|c|}
\hline $\begin{array}{l}\text { Antifungal } \\
\text { Agent }\end{array}$ & & $\begin{array}{l}\text { C. } \\
\text { albicans }\end{array}$ & $\begin{array}{l}\text { C. } \\
\text { glabrata }\end{array}$ & $\begin{array}{l}\text { C. } \\
\text { parapsilosis }\end{array}$ & $\begin{array}{l}\text { C. } \\
\text { krusei }\end{array}$ & C. kefry & $\begin{array}{l}\text { C. } \\
\text { hellenica }\end{array}$ & $\begin{array}{l}\text { C. } \\
\text { tropicalis }\end{array}$ & $\begin{array}{l}\text { S. } \\
\text { cereviasea }\end{array}$ & $\begin{array}{l}\text { C. } \\
\text { albicans } \\
\text { ATCC } \\
1021\end{array}$ \\
\hline & & $\mathrm{N}(\%)$ & $\mathrm{N}(\%)$ & $\mathrm{N}(\%)$ & $\mathrm{N}(\%)$ & $\mathrm{N}(\%)$ & $\mathrm{N}(\%)$ & $\mathrm{N}(\%)$ & $\mathrm{N}(\%)$ & $\mathrm{N}(\%)$ \\
\hline \multirow[t]{3}{*}{ Itraconazole } & S & $3(25.0)$ & $1(50.0)$ & $2(28.6)$ & $0(0.0)$ & $1(50.0)$ & $0(0.0)$ & $2(22.2)$ & $1(100.0)$ & $0(0.0)$ \\
\hline & I & $6(50.0)$ & $1(50.0)$ & 1 (14.3) & $2(100.0)$ & $0(0.0)$ & $0(0.0)$ & $4(44.5)$ & $0(0.0)$ & $1(100.0)$ \\
\hline & $\mathrm{R}$ & $3(25.0)$ & $0(0.0)$ & $4(57.1)$ & $0(0.0)$ & $1(50.0)$ & $1(100.0)$ & $3(33.3)$ & $0(0.0)$ & $0(0.0)$ \\
\hline \multirow[t]{3}{*}{ Nystatin } & $\mathrm{S}$ & $2(16.7)$ & $0(0.0)$ & $3(42.9)$ & $1(50.0)$ & $0(0.0)$ & $1(100.0)$ & 1 (11.1) & $0(0.0)$ & $0(0.0)$ \\
\hline & I & $6(50.0)$ & $2(100.0)$ & $3(42.9)$ & $0(0.0)$ & $1(50.0)$ & $0(0.0)$ & $3(33.3)$ & $1(100.0)$ & $1(100.0)$ \\
\hline & $\mathrm{R}$ & $4(33.3)$ & $0(0.0)$ & $1(14.2)$ & $1(50.0)$ & $1(50.0)$ & $0(0.0)$ & $5(55.6)$ & $0(0.0)$ & $0(0.0)$ \\
\hline \multirow[t]{3}{*}{ Ketoconazole } & $\mathrm{S}$ & $7(58.3)$ & $2(100.0)$ & $5(71.4)$ & $1(50.0)$ & $0(0.0)$ & $0(0.0)$ & $5(55.6)$ & $1(100.0)$ & $1(100.0)$ \\
\hline & I & 2 (16.7) & $0(0.0)$ & $0(0.0)$ & $0(0.0)$ & $1(50.0)$ & $0(0.0)$ & $2(22.2)$ & $0(0.0)$ & $0(0.0)$ \\
\hline & $\mathrm{R}$ & $3(25.0)$ & $0(0.0)$ & $2(20.0)$ & $1(50.0)$ & $1(50.0)$ & $1(100.0)$ & $2(22.2)$ & $0(0.0)$ & $0(0.0)$ \\
\hline \multirow[t]{3}{*}{ Fluconazole } & $\mathrm{S}$ & $6(50.0)$ & $1(50.0)$ & $6(85.7)$ & $0(0.0)$ & $1(50.0)$ & $0(0.0)$ & $2(22.2)$ & $0(0.0)$ & $1(100.0)$ \\
\hline & I & $3(25.0)$ & $0(0.0)$ & $0(0.0)$ & $0(0.0)$ & $0(0.0)$ & $0(0.0)$ & $5(55.6)$ & $0(0.0)$ & $0(0.0)$ \\
\hline & $\mathrm{R}$ & $3(25.0)$ & $1(50.0)$ & $1(14.3)$ & $1(100.0)$ & $1(50.0)$ & $1(100.0)$ & $2(22.2)$ & $1(100.0)$ & $0(0.0)$ \\
\hline \multirow[t]{3}{*}{ Terbinafine } & $S$ & $1(8.3)$ & $1(50.0)$ & $1(14.3)$ & $0(0.0)$ & $0(0.0)$ & $0(0.0)$ & 1 (11.1) & $1(100)$ & $0(0.0)$ \\
\hline & I & $6(50.0)$ & $0(0.0)$ & $2(28.6)$ & $0(0.0)$ & $0(0.0)$ & $0(0.0)$ & $0(0.0)$ & $0(0.0)$ & $0(0.0)$ \\
\hline & $\mathrm{R}$ & 5 (41.7) & $1(50.0)$ & 4 (57.1) & $2(100)$ & $2(100)$ & $1(100)$ & 8 (88.9) & $0(0.0)$ & $1(100)$ \\
\hline \multirow[t]{3}{*}{ Griseofulvin } & $S$ & $0(0.0)$ & $0(0.0)$ & $0(0.0)$ & $0(0.0)$ & $0(0.0)$ & $0(0.0)$ & $0(0.0)$ & $0(0.0)$ & $0(0.0)$ \\
\hline & I & $0(0.0)$ & $0(0.0)$ & $0(0.0)$ & $0(0.0)$ & $0(0.0)$ & $0(0.0)$ & $0(0.0)$ & $0(0.0)$ & $0(0.0)$ \\
\hline & $\mathrm{R}$ & $12(100.0)$ & $2(100.0)$ & $7(100.0)$ & $2(100.0)$ & $2(100.0)$ & $1(100.0)$ & $9(100.0)$ & $1(100.0)$ & $1(100.0 .0)$ \\
\hline
\end{tabular}

Several chromogenic substrates-containing media have been developed to facilitate the rapid identification of Candida species.
Chromogenic media are frequently used in the direct and indirect identification of yeasts because of the unique colour produced on 
these media by Candida species. Chrom Agar Candida was employed to differentiate Candida species by colour and morphology. The API $32 \mathrm{C}$ method enabled the correct identification of isolates. The visual interpretation might sometimes be different and require expertise than in a routine clinical laboratory.

In this study, Candida species had the highest susceptibility rate to ketoconazole, effective against six Candida species. This is inconsistent with the report of Akortha et al., which observed high susceptibility to Fluconazole among Candida species. [14] Nystatin, itraconazole and ketoconazole showed an excellent pattern of effectiveness against Candida species in agreement with the findings of Al-abeibe et al., which reported that Candida species were susceptible to Nystatin, itraconazole and ketoconazole. [20]

All the Candida species isolated in the present study were resistant to griseofulvin. Half of $C$. albicans isolated were sensitive to fluconazole, in agreement with the finding of Ekpo et al., in Cameroon [21] but $C$. hellenica was only sensitive to Nystatin. The C. grabrata had the highest sensitivity rate to intraconazole and ketoconazole. The C. parapsilosis had susceptibility rate of $86 \%$ and $71 \%$ to fluconazole and ketoconazole respectively. Overall, Candida species had the highest susceptibility rate to ketoconazole.

\section{Conclusion}

Candida albicans was a significant cause of candiduria in a population of adults with UTIs. The speciation of Candida using Chrome agar showed great benefit, but API 32C was better. Candida species showed various degrees of susceptibility patterns to different antifungal agents. Therefore, speciation and susceptibility testing for fungal isolates should be employed routinely in laboratories.
Authors' Contributions: AOV conceived the study and collected the data while OOA and AOV designed the study. All the authors participated in the literature review, data analysis and interpretation and manuscript drafting. OOA and LIA revised the manuscript for sound intellectual content. All the authors approved the final version of the manuscript.

Conflict of Interest: None.

Funding: Self-funded.

Publication History: Submitted 04 May 2021; Accepted 22 November 2021.

\section{References}

1. Behzadi P, Behzadi E, Ranjbar R. Urinary tract infections and Candida albicans. Cent Eur J Urol 2015; 68: 96-101. https://doi.org/10.5173/ceju

2. Colombo AL, Guimarães T. Candidúria: umaabordagemclínica e terapêutica. Rev Soc Bras Med Trop 2007; 4: 332-337.

3. Rodrigues D. Candidúria. Revisão Atual RBPS Fortaleza 2011; 24: 142-150.

4. Sobel JD, Vazaquez JA. Fungal infections of the urinary tract. World J Urol 1999; 17: 410-414.

5. Adjapong G, Hale M, Garrill A. An investigation of the distribution of Candida species in genitourinary candidiasis and pelvic inflammatory disease from three locations in Ghana. Afr J Microbiol Res 2014; 8: 470-475. https://doi.org/10.5897/AJMR2013.6407

6. Tsaku PA, Kaigama IS, Uzoeto JS, Didiugwu CM, Ajima JN. Prevalence of Candiduria in a University Campus in Central Nigeria. Ann Microbiol Infect Dis 2018; 4: 1-5.

7. Passos XS. Candida colonisation in intensive care unit patients' urine. Mem Inst Oswaldo Cruz 2005; 100: 925-928.

8. Cowen LE, Sanglard D, Howard SJ, Rogers PD, Perlin DS. Mechanisms of Antifungal Drug Resistance. Cold Spring Harb Perspect Med 2015; 5: a019752. 
https://doi.org/10.1101/cshperspect.a019 $\underline{752}$

9. Kołaczkowska A, Kołaczkowski M. Drug resistance mechanisms and their regulation in non-albicans Candida species. J Antimicrob Chemother 2016; 71: 1438-1450.

https://doi.org/10.1093/jac/dkv445

10. Clinical and Laboratory Standards Institute (2008). Reference method for broth dilution antifungal susceptibility testing of yeasts; approved standard-Third Edition. CLSI document M27-A3(28). CLSI, 940 West Valley Road, Suite 1400, Wayne, Pennsylvania 19087-1898 USA, 2002.

11. Felix CA, Josiah L, Emmanuel I, Kingsley HE, Susan EE, Martin A, et al. Incidence of Urinary Tract Infections among outpatients attending a clinic in University of Calabar Teaching Hospital (UCTH), Calabar, Cross Rivers State. Pacific J Sci Technol 2013; 14: 384-387.

12. Gharaghani M, Taghipour S, Halvaeezadeh M, Mahmoudabadi AZ. Candiduria; a review article with specific data from Iran. Turk J Urol 2018; 44: 445452.

https://doi.org/10.5152/tud.2018.54069

13. Yismaw G, Asrat D, Woldeamanuel Y, Unakal C. Prevalence of candiduria in diabetic patients attending Gondar University Hospital, Gondar, Ethiopia. Iran J Kidney Dis 2013; 7: 102-107.

14. Akortha EE, Nwanujo VO, Chikwe NO. Antifungal resistance among Candida species from patients with genitourinary infections isolates in Bennin City, Nigeria. Afr J Microbiol Res 2009: 3: 694-699. https://doi.org/10.5897/AJMR.9000065

15. Okungbowa FO, Isuehuemhen OS, Dede A. The distribution of frequency of
Candida species in the genitourinary tract among symptomatic individuals in Nigerian cities. Rev Iberoam Micol 2003; 20: 60-63.

16. Hollandia J, Young ML, Lee O. Vulvovaginal carriage of yeast other than Candida albicans. Sex Transm Infect 2003; 79: 249-250.

17. Enweani IB, Gugnani HC, Okobia R, Ojo SB. Effect of contraceptives on the prevalence of vaginal colonisation with Candida species in Edo state, Nigeria. Rev. Iberoam Micol 2000; 18: 171-173.

18. Ozhak-Baysan B, Ogunc D, Colak D, Ongut G, Donmez L, Vural T. Distribution and antifungal susceptibility of Candida species causing nosocomial candiduria. Med Mycol 2012; 50: 529-532. https://doi.org/10.3109/13693786.2011.61 $\underline{8996}$

19. Salehi M, Ghasemian A, Shokouhi, Mosteafavi SK, Nojoomi F, Ashaiani D. The epidemiology of Candida species isolated from urinary tract infections. Arch Clin Infect Dis 2016; 11. https://doi.org/10.5812/archoid.37743

20. Hanan M, Al-Abeid H.M. Isolation of characterisation of candida species in Johanian cancer patients: prevalence, pathogenic determinant and antifungal sensitivity. Jpn J Infect Dis 2004; 16: 279284.

21. Ekpo IA, Kechia FA, and Iwewe YS, Ngueguim1 AD, Nangwat1 C and Dzoyemi JP. Species distribution and antifungal susceptibility profile of Candida spp isolated from the urine of hospitalised patients in Dschang District Hospital, Cameroon. Int J Biol Chem Sci 2017; 11: 1212-1221. https://doi.org/10.4314/ijbcs.v11i3.23 source is adequately cited and credited. 